\title{
Рекомендации по лечению пациентов с прогрессирующим или метасmamuческим почечно-клеточным раком комбинацией ленватиниба и эверолимуса*
}

\author{
E. Grande, H. Glen, J. Aller, G. Argenziano, M.J. Lamas, P. Ruszniewski, J.L. Zamorano, K. Edmonds, S. Sarker, M. Staehler, J. Larkin
}

На сегодняшний день существует несколько вариантов терапии 2-й линии для пациентов с почечно-клеточным раком после неудачи 1-й линии терапии ингибиторами тирозинкиназ. Недавно были одобрены для лечения кабозантиниб, ниволумаб и комбинация ленватиниб + эверолимус. Отсутствие надежных биомаркеров, а также ограниченность данных проспективных сравнений различных препаратов затрудняют выбор тактики лечения 2-й линии в рутинной клинической практике.

В настоящем обзоре мы описываем профиль безопасности комбинации ленватиниб + эверолимус при почечно-клеточном раке. Данная комбинация обеспечила наиболее высокие показатели объективного ответа на терапию, выживаемости без прогрессирования и общей выживаемости в исследованиях с перекрестным дизайном. В то же время профиль безопасности этой комбинации, включая частоту общих и тяжелых нежелательных явлений, процент пациентов, которым потребовалось снижение дозы или полная отмена лечения, был менее благоприятным по сравнению с доступными вариантами монотерапии. Это позволяет предположить, что более тщательный контроль токсических реакций может способствовать достижению максимальной активности этих двух средств, одновременно защищая пациентов от неоправданного вреда.

Цель - разработка междисциплинарных рекомендаций для пациентов и лии, осуществляющих уход за ними, перед началом лечения комбинацией ленватиниб + эверолимус, в том числе по контролю терапии с точки зрения повседневной клинической практики.

Основные положения:

- Комбинация ленватиниба и эверолимуса одобрена для лечения пациентов с почечно-клеточным раком, рефрактерным к терапии ингибиторами тирозинкиназ, на основании высоких показателей объективного ответа, длительной выживаемости без прогрессирования и общей выживаемости.

- Профиль безопасности этой комбинации включает высокую частоту общих и тяжелых нежелательных явлений, при этом многие пациенты нуждаются в снижении дозы или прекращении лечения. Это позволяет предположить, что более эффективный контроль токсических реакций может способствовать достижению максимальной активности комбинации препаратов, одновременно защищая пациентов от неоправданного вреда.

- В этой статье мы представили мультидисциплинарные рекомендации по консультированию пациентов и лии, осуществляющих уход за ними, перед началом лечения ленватинибом в комбинации с эверолимусом, в том числе по контролю терапии с точки зрения повседневной клинической практики.

Ключевые слова: коррекция дозы, эверолимус, ленватиниб, оптимизация, почечно-клеточный рак, терапия, безопасность

Для цитирования: Grande E., Glen H., Aller J. и др. Рекомендации по лечению пациентов с прогрессирующим или метастатическим почечно-клеточным раком комбинацией ленватиниба и эверолимуса. Онкоурология 2020;16(4):61-81.

DOI: $10.17650 / 1726-9776-2020-16-4-61-81$

(cc) BY 4.0

\section{1. Введенше}

У большинства пациентов с раком почки диагностируют почечно-клеточный вариант опухоли (ПКР) [1]. Основным генетическим триггером светлоклеточного варианта ПКР являются мутации гена-супрессора опухолевого роста - гена фон Гиппеля-Линдау (Von Hippel-Lindau, $V H L$ ), что приводит к повышению продукции и высвобождению факторов проангиогенеза [2, 3]. По данным молекулярно-генетических исследований $28 \%$ случаев светлоклеточного ПКР имеют определенные изменения, влияющие на сигнальный путь PI3K/Akt/mTOR, что, вероятно, играет роль в прогрессии опухоли [4].
До недавнего времени существовало 2 основных варианта терапии 2-й линии, которые чаще других назначались для лечения пациентов с ПКР: пероральный ингибитор mTOR эверолимус $[5,6]$ и ингибитор рецепторов сосудистого эндотелиального фактора роста (vascular endothelial growth factor receptor, VEGFR) акситиниб [7]. В последнее десятилетие ингибиторы ангиогенеза и ингибиторы mTOR широко использовались последовательно после предшествующей монотерапии ингибиторами тирозинкиназ (ИТК), что способствовало увеличению общей выживаемости (ОВ) и повышению качества жизни пациентов $[8,9]$. Помимо комбинации ленватиниб + эверолимус (ЛЕНЭВЕ)

*Публикуется на русском языке с разрешения авторов. Оригинал: Grande E., Glen H., Aller J. et al. Recommendations on managing lenvatinib and everolimus in patients with advanced or metastatic renal cell carcinoma. Expert Opinion on Drug Safety 2017. DOI: 10.1080/14740338.2017.1380624. 
$[10,11]$ еще 2 препарата были недавно одобрены для лечения пациентов с ПКР после прогрессирования заболевания на фоне ингибиторов ангиогенеза (после как минимум одной линии терапии): ниволумаб - ингибитор рецептора программируемой смерти 1 (PD-1) [12], кабозантиниб - ИТК, действующий на VEGFR, рецептор фактора роста гепатоцитов (MET) и AXLрецептор [13, 14]. Было установлено, что и ниволумаб, и кабозантиниб обеспечивают бо́льшую ОВ по сравнению с монотерапией эверолимусом при назначении во 2-й и 3-й линии лечения $[12,14]$. Кроме этого, ниволумаб способствовал улучшению качества жизни пациентов с ПКР по сравнению с эверолимусом [15].

Среди врачей, имеющих большой опыт применения ИТК в повседневной практике, есть устоявшееся мнение в отношении прямой взаимосвязи между дозой ИТК и клиническим исходом, а также развитием токсических реакций. Чем больше доза препарата, тем выше будет его концентрация в плазме крови и, следовательно, можно ожидать лучшие показатели ответа на терапию, выживаемости без прогрессирования и ОВ [16-19]. Также в литературе имеются данные, подтверждающие, что степень тяжести нежелательных явлений (НЯ) может быть ассоциирована с лучшими исходами у пациентов, получающих монотерапию ингибиторами mTOR [20]. Таким образом, поддержание запланированной дозы - ключевой фактор для достижения наилучших клинических результатов применения ИТК и ингибиторов mTOR в рутинной практике. Если врач имеет достаточный опыт контроля побочных эффектов, правильного подбора дозы и поддержания графика приема препаратов, то его пациент с ПКР имеет более высокую вероятность получить максимальную пользу от лечения. Поскольку НЯ являются следствием изменений в различных органах и системах организма, очевидно, что глубокие знания и понимание их патофизиологических и клинических последствий, а также мультидисциплинарный подход к лечению нежелательных реакций, сформировавшихся вследствие применения ИТК или ингибиторов $\mathrm{mTOR}$, помогут воздействовать на ожидаемые клинические исходы.

Мы постарались обобщить имеющиеся данные о комбинации ЛЕНЭВЕ и предоставить врачам практические рекомендации по обучению пациентов, мониторингу и ведению больных с ПКР, получающих эту комбинацию.

\section{2. Ленватиниб + эверолимус: механцзм действия}

Ленватиниб является мультитаргетным ингибитором тирозинкиназ, действующим на VEGFR1-3, рецепторы фактора роста фибробластов 1-4 (fibroblast growth factor receptors 1-4, FGFR1-4), рецепторы тромбоцитарного фактора роста $\beta$ (platelet-derived growth factor receptors $\beta$, PDGFR- $\beta$ ) и другие тирозинкиназные рецепторы, включая RET и KIT [21, 22]. На сегодняшний день ленватиниб одобрен в США, Европе и Японии для лечения метастатического, прогрессирующего, рефрактерного к радиоактивному йоду дифференцированного рака щитовидной железы в качестве монотерапии и в комбинации с эверолимусом для лечения взрослых пациентов с прогрессирующим ПКР после предшествующей VEGF-таргетной терапии [23-26].

Эверолимус - ингибитор киназы mTOR, который впервые был одобрен в 2009 г. для лечения прогрессирующего ПКР после терапии сунитинибом или сорафенибом [27]. Кроме этого, эверолимус был одобрен для лечения гормон-рецептор-положительного HER2отрицательного рака молочной железы в комбинации с экземестаном после терапии летрозолом или анастрозолом, а также для пациентов с нерезектабельными или метастатическими прогрессирующими нейроэндокринными опухолями поджелудочной железы, желудочно-кишечного тракта или легкого.

Молекулярное обоснование для применения комбинации ингибитора ангиогенеза и блокатора пути $\mathrm{PI} 3 \mathrm{~K} / \mathrm{Akt} / \mathrm{mTOR}$ заключается в обеспечении синергии их действия у пациентов с ПКР, когда, как уже упоминалось выше, оба эти компонента являются ключевыми в канцерогенезе.

\section{3. Ленватиниб + эверолимус: фармакокинетика u фармакодинамика}

Время достижения максимальной концентрации в плазме крови при пероральном приеме ленватиниба в виде монотерапии обычно составляет от 1 до 4 ч [26, 28, 29]. Существует несколько факторов, оказывающих незначительное, хотя и достоверное влияние на фармакокинетику ленватиниба (не рассматриваются как клинически значимые и требующие коррекции дозы): масса тела, маркеры функции печени (щелочная фосфатаза и альбумин) и одновременное введение индукторов и ингибиторов СҮРЗА 4 . Доза, пол, раса, возраст, статус по шкале ECOG, маркеры функции почек или щитовидной железы не оказывают влияния на фармакокинетику ленватиниба [30].

\section{4. Ленватиниб + эверолимус: эффективность}

Эффективность ленватиниба изучалась в рандомизированном многоцентровом международном открытом исследовании фазы II НОРЕ-205, в котором препарат назначался в качестве 2-й линии терапии пациентам с распространенным или метастатическим светлоклеточным ПКР после одной линии анти-VEGF-терапии [10]. Все участники исследования $(n=153)$ были рандомизированы в 3 группы в соотношении 1:1:1. Пациенты групп сравнения получали эверолимус в дозе 10 мг/сут или ленватиниб в дозе 24 мг/сут (монотерапия), а пациенты экспериментальной группы получали оба препарата в дозах 18 и 5 мг/сут соответственно. Независимый анализ полученных через 12,9 мес (медиана) рентгенологических снимков показал, что комбинация ЛЕНЭВЕ 
превосходила монотерапию эверолимусом по частоте объективного ответа (35 (22-50) \% против 0 (0-7) \% в группе сравнения), выживаемости без прогрессирования (медиана 12,8 (7,4-17,5) мес против 5,6 (3,6-9,3) мес в группе сравнения; отношение рисков (ОР) 0,45; $95 \%$ доверительный интервал (ДИ) $0,27-0,79 ; p=0,0029)$ и ОВ (25,5 (16,4-не достигнута) мес против 15,4 (11,8-19,6) мес в группе сравнения; ОР 0,51; 95 \% ДИ 0,30-0,88; $p=0,024)$ [11]. Анализ post hoc, ограниченный небольшим числом пациентов, показал улучшение исходов независимо от предшествующей VEGF-таргетной терапии [26, 31]. В табл. 1 представлены результаты оценки эффективности новых препаратов, одобренных в качестве терапии 2-й линии для пациентов с ПКР.

\section{5. Ленватиниб + эверолимус: профиль безопасности}

Наиболее частыми НЯ, наблюдавшимися в группе ЛЕНЭВЕ в исследовании НОРЕ-205, были диарея (85\%), повышенная утомляемость или астения (59 \%), рвота (45\%) и артериальная гипертензия (41 \%) (табл. 2) [10]. У 71 \% пациентов, получавших ЛЕНЭВЕ, отмечены НЯ III или IV степени тяжести, включая диарею (20\%), повышенную утомляемость (14\%), гипертонию (14\%), рвоту (8 \%) и гипертриглицеридемию (8\%).

Профиль безопасности комбинации ЛЕНЭВЕ согласуется с известными токсическими реакциями для каждого отдельного препарата.

Наиболее частыми ( $\geq 30$ \% пациентов) НЯ, регистрируемыми на фоне монотерапии ленватинибом у пациентов с распространенным дифференцированным раком щитовидной железы, были (в порядке убывания встречаемости): артериальная гипертензия, диарея, снижение аппетита, массы тела, повышенная утомляемость, тошнота, протеинурия, стоматит, рвота, дисфония, головная боль и ладонно-подошвенная эритродизестезия [28, 31].

У больных ПКР, получавших ленватиниб в виде монотерапии, чаще всего регистрировали диарею, снижение аппетита, тошноту, повышенную утомляемость или астению, снижение массы тела, дисфонию, запоры, рвоту, гипотиреоз, артериальную гипертензию [10, 31].

Наиболее распространенными НЯ, ассоциированными с приемом эверолимуса в клинических испытаниях среди пациентов с прогрессирующим раком, были стоматит, сыпь, повышенная утомляемость, диарея, инфекции, тошнота, снижение аппетита, анемия, дисгевзия, пневмонит, гипергликемия, снижение массы тела, зуд, астения, периферические отеки, гиперхолестеринемия, эпистаксис и головная боль [31].

Среди пациентов с ПКР, получавших ЛЕНЭВЕ, чаще всего отмечались диарея, повышенная утомляемость, снижение аппетита, рвота, тошнота, артериальная гипертензия, гипертриглицеридемия, кашель, стоматит, периферические отеки, снижение массы тела, одышка и гиперхолестеринемия [31].
Сравнение известных профилей безопасности ленватиниба и эверолимуса как отдельных препаратов с профилем безопасности комбинации ЛЕНЭВЕ позволило выявить 11 НЯ, наиболее характерных именно для совместного использования этих 2 средств: диарея, гиперхолестеринемия, гипотиреоз, гипертриглицеридемия, повышенная утомляемость, рвота, острая почечная недостаточность, обезвоживание, анемия, гипергликемия и зуд [31].

В исследовании НОРЕ-205 [10] 1 пациент группы ЛЕНЭВЕ умер по причине внутримозгового кровоизлияния, 3 летальных исхода в группе монотерапии ленватинибом по причине инфаркта миокарда, внутричерепного кровоизлияния и сепсиса, 2 пациента в группе сравнения (монотерапия эверолимусом) погибли по причине сепсиса и дыхательной недостаточности.

Клинический исход лечения терапии 1-й линии не оказывает особого влияния на выбор препарата 2-й линии лечения, поскольку клинический ответ на 2-ю линию терапии ингибитором VEGFR не зависит от ответа на 1-ю линию терапии ингибитором VEGFR [32]. Однако токсические реакции, связанные c приемом препарата в 1-й линии, могут препятствовать применению другого ИТК в рамках терапии 2-й линии, даже если кумулятивная токсичность наблюдается не всегда [33-36].

В исследовании НОРЕ-205 все пациенты группы ЛЕНЭВЕ ранее получали таргетную анти-VEGF-терапию (сунитиниб, пазопаниб, тивозаниб, акситиниб, сорафениб и др.) и были включены в исследование в течение 9 мес после завершения предыдущей линии лечения [10]. Медиана продолжительности лечения ингибитором VEGF в 1-й линии составила 9,8 $(2,0-66,2)$ мес, медиана времени между окончанием таргетной антиVEGF-терапии и включением в исследование HOPЕ-205 составила 1,5 мес (интерквартильный диапазон 1,1-2,3 мес) [10, 31]. До сих пор нет четкого понимания в отношении кумуляции нежелательных реакций при последовательном использовании двух ИТК, а также как можно снизить подобный эффект правильным подбором ИТК с различными профилями токсичности.

В табл. 2 представлены показатели безопасности и потребовавшие изменения дозы токсические реакции, которые наблюдались в основных исследованиях, изучавших новые препараты во 2-й линии для лечения ПКР. В целом профиль безопасности ЛЕНЭВЕ сопоставим с таковым других ИТK VEGFR, включая акситиниб и кабозантиниб.

Медиана времени до регистрации основного НЯ показана в табл. 3. Диарея и артериальная гипертензия, как правило, возникают раныше остальных. Эпизод артериальной гипертензии был зарегистрирован в первом цикле у 21 \% пациентов, получавших ЛЕНЭВЕ [31]. Протеинурию чаще всего фиксировали в течение первых 2 циклов лечения [31]. Геморрагические явления 


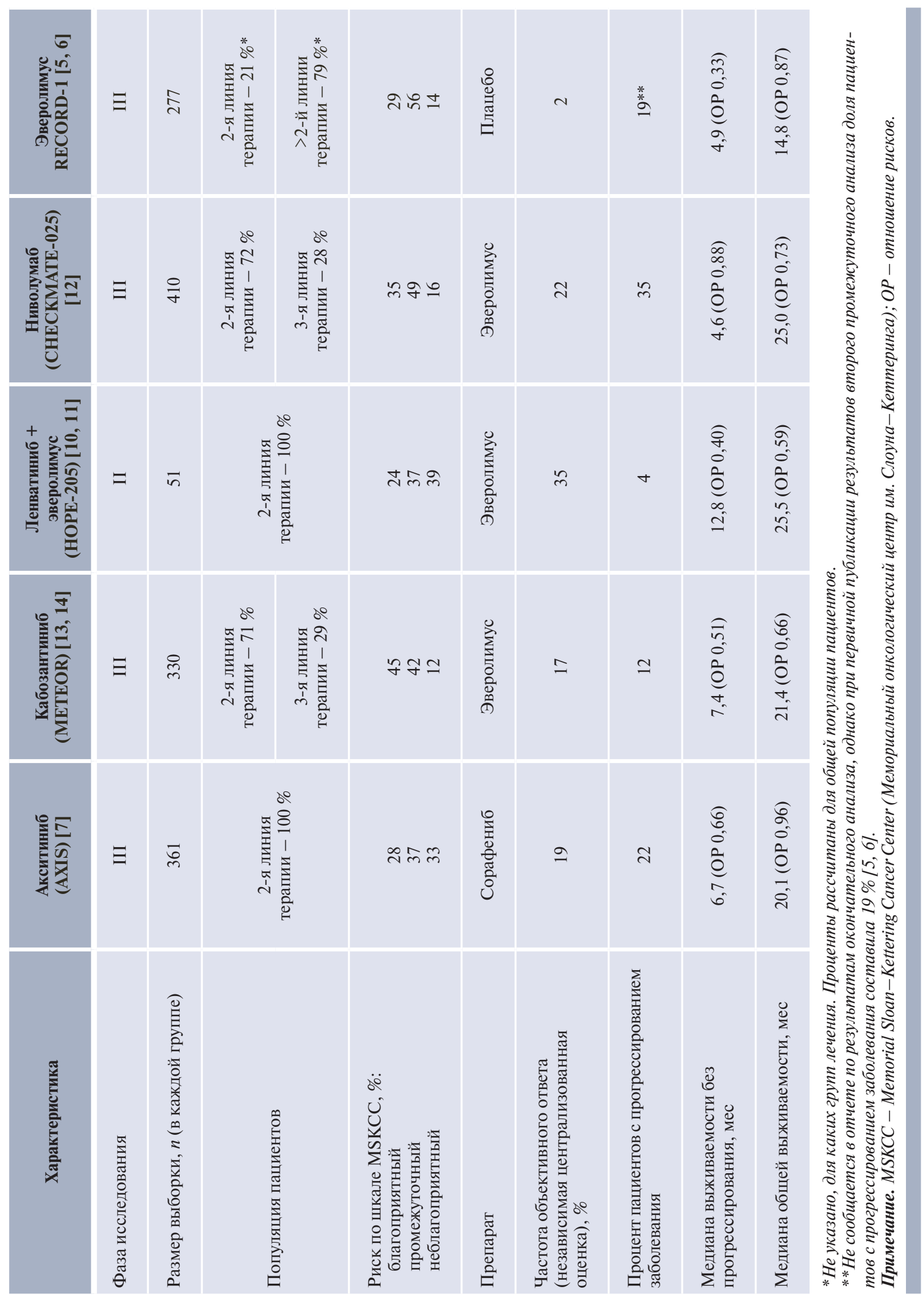




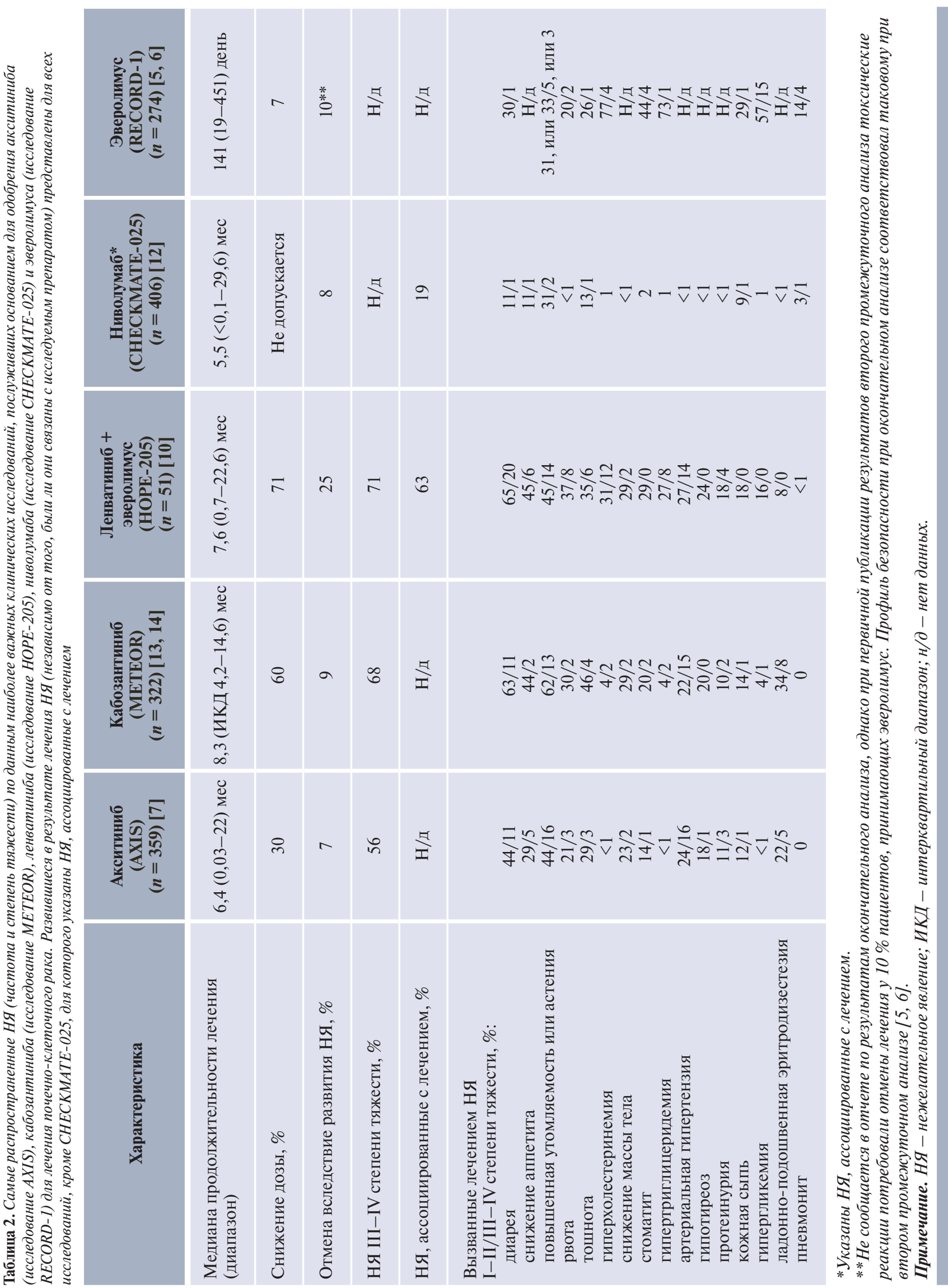



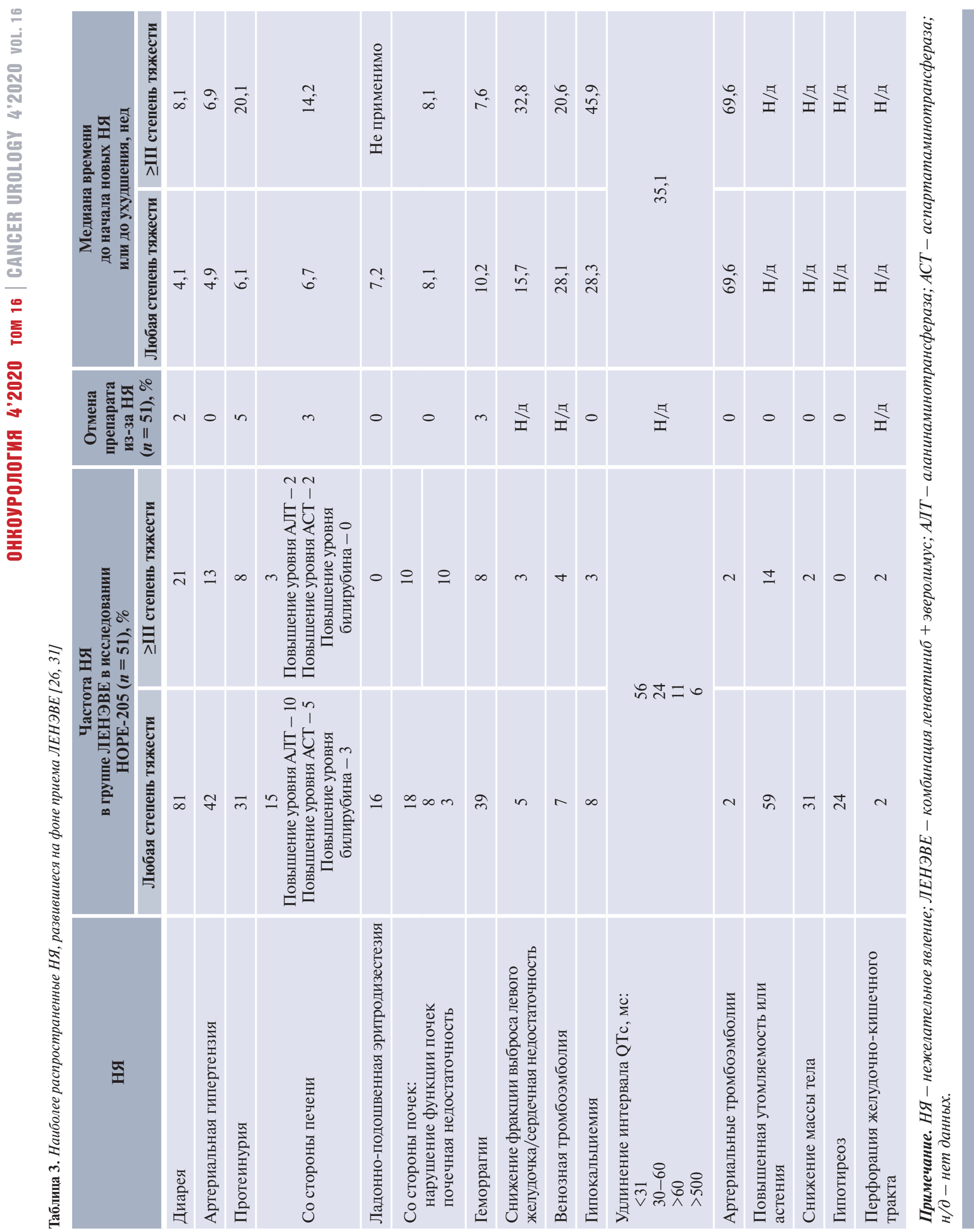
в основном возникали в начале терапии, затем их частота уменьшалась после 3 циклов [31].

В целом НЯ также возникают из-за ухудшения общего состояния здоровья пациента в контексте распространенного заболевания, которое является терминальным, агрессивным и претерпело длительную эволюцию.

\section{6. Ленватuнuб + эверолимус: ведение пациентов}

\section{1. Перед назначением комбинации ленватиниб +} эверолимус

В повседневной практике перед назначением ЛЕНЭВЕ врач должен провести физикальный осмотр, проанализировать результаты биохимического и общего анализа (рис. 1).

\subsection{1. Клинические и лабораторные обследования пациентов}

\subsubsection{1. Анамнез}

При назначении ЛЕНЭВЕ особое внимание следует уделять наличию у пациента сахарного диабета, неконтролируемой артериальной гипертензии, легочных заболеваний, сердечной недостаточности или неконтролируемых эндокринопатий. Важно отметить, что данные патологии не являются противопоказаниями для назначения ЛЕНЭВЕ, но должны хорошо контролироваться еще до начала терапии. Например, артериальная гипертензия должна быть скорректирована с помощью антигипертензивных средств до начала терапии ЛЕНЭВЕ.

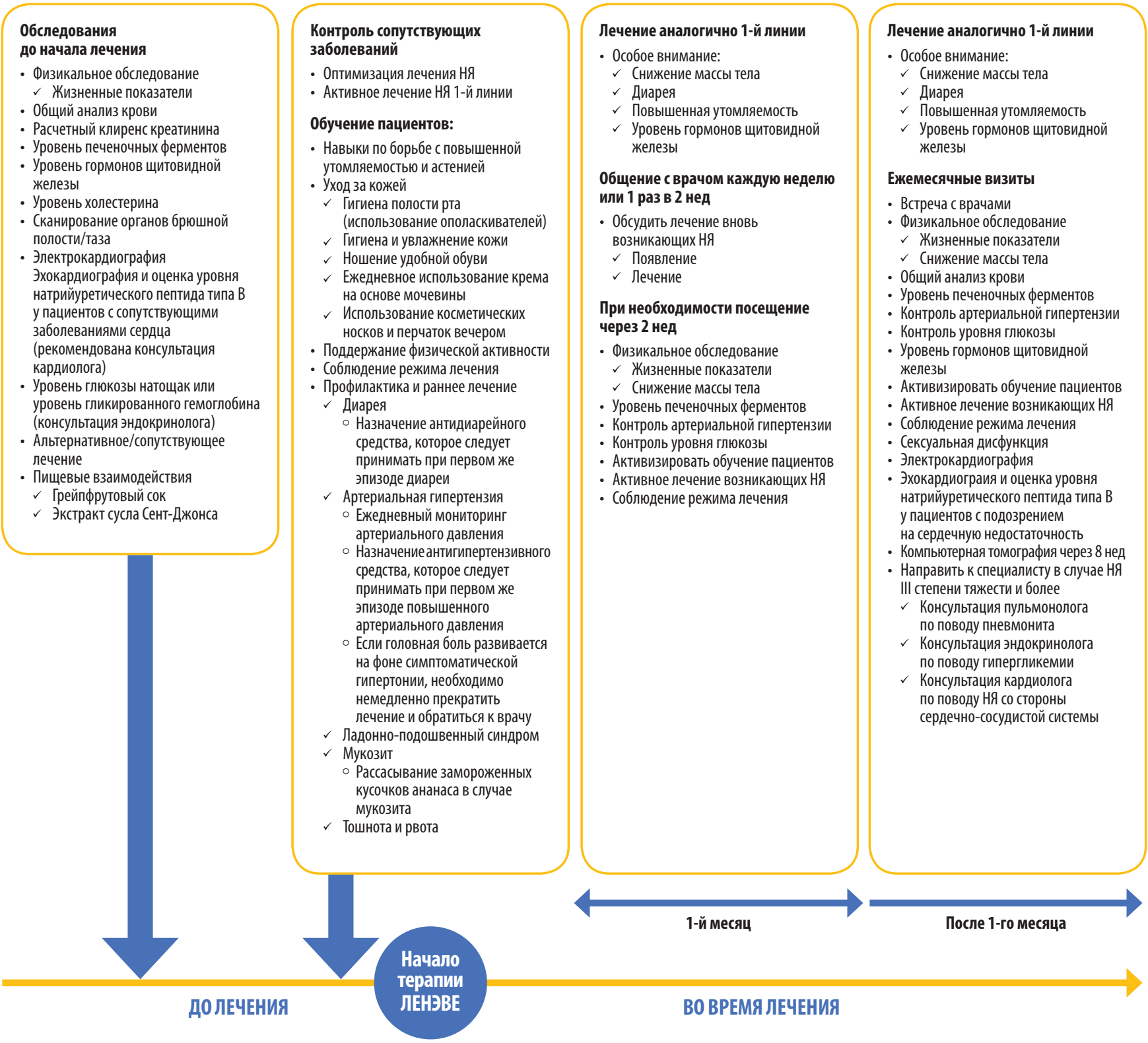

ечение аналогично 1-й лини

собое внимание:

Диарея

Повышенная утомляемость

Уровень гормонов щитовидно

\section{или 1 раз в 2 нед}

Обсудить лечение внов возникающих НЯ

Появление

\section{через 2 нед}

Жизненные показатели

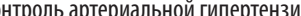

Активное лечение возникающих НЯ

ипертензи ортериальй Назначениеантигипертензивного средства, которое следует принимать при первом же артериального давления немедленно прекратить

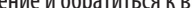
мукозита

$\checkmark$ Тошнота и рвота

Рис. 1. Рекомендации по мероприятиям и срокам их проведения, которых следует придерживаться до и во время лечения ЛЕНЭВЕ 


\subsubsection{2. Взаимодействие с другими лекарственными препаратами}

Как ленватиниб, так и эверолимус являются субстратами печеночных ферментов и транспортеров. Потенциал клинически значимых лекарственных взаимодействий ленватиниба считается достаточно низким, несмотря на ингибирование CYP3A4, CYP2C8, UGT1A4, UGT1A1, OCT2, OATP1B1, OAT1, OAT3 in vitro [31], но он может оказаться более значимым при использовании ленватиниба в комбинации с эверолимусом. Тем не менее попрежнему важно подробно обсудить с пациентом препараты, которые он принимает, чтобы предвидеть возможные лекарственные взаимодействия с ленватинибом или эверолимусом. Наиболее часто онкологические больные принимают антигипертензивные, противодиарейные (лоперамид) препараты, препараты для лечения патологии щитовидной железы, антидепрессанты, антикоагулянты (варфарин, кумарол), опиаты и омепразол.

В исследовании НОРЕ-205 пациенты группы ЛЕНЭВЕ также получали антигипертензивные препараты
$(82,4 \%$, в основном амлодипин - 49,0 \%), лоперамид $(58,8 \%)$, препараты для лечения заболеваний щитовидной железы или левотироксин (52,9 \%) [31]. Кроме этого, следует пересмотреть применение трав и других растительных средств с фармакологической активностью, которые могут взаимодействовать с эверолимусом или ленватинибом.

Удлинение интервала QT >500 мс считается значимым фактором риска развития желудочковых аритмий [37]. Удлинение интервала QTс $>500$ мс было зафиксировано только у $6 \%$ пациентов, получавших ЛЕНЭВЕ. Однако одновременное использование других лекарственных препаратов, а именно лоперамида, может увеличить риск удлинения интервала QТ и, следовательно, аритмии [38]. Электролитный дисбаланс из-за диареи тоже может увеличить риск развития аритмии.

В табл. 4 приводится краткое описание часто применяемых лекарственных средств, которые могут взаимодействовать с ленватинибом или эверолимусом. В настоящее время не рекомендуется коррекция дозы

Таблица 4. Взаимодействие ленватиниба и эверолимуса с другими лекарственными средствами. Препараты, которые следует применять с осторожснотью при одновременном назначении с ЛЕНЭВЕ. Клекарственным средствам, которые используются больщинством пациентов при лечении ЛЕНЭВЕ, относятся антигипертензивные, антидиарейные (лоперамид) средства, препараты для лечения заболеваний шитовидной железы, антидепрессанты, омепразол, антикоагулянты. Информацию о потенциальных взаимодействиях с препаратами, пролонгирующими интервал QT, можно найти на сайте https://crediblemeds.org (дата обращения 24.03.2017)

Сильные ингибиторы СYР3А4 ( $\geq 5$-кратное увеличение AUC или более чем $80 \%$ снижение клиренса субстратов СУРЗА)

Сильные активаторы СҮР3А4 (снижают AUC чувствительных субстратов определенного метаболического пути на $\geq 80 \%$ )

Ингибиторы Р-гликопротеина

Препараты, увеличивающие интервал QT

Азольные противогрибковые препараты

Макролиды

Кетолиды

Препараты против вируса иммунодефицита человека

и гепатита C

\section{Антидепрессанты}

Травы и растительные препараты

Противотуберкулезный препарат

Противоэпилептический препарат

Травы и растительные препараты

Амиодарон, кларитромицин, циклоспорин, каптоприл, дилтиазем (умеренный), карведилол, дронедарон, итраконазолб кетоконазол, ритонавирб хинидин, саквинавир, телапревир, верапамил, эритромицин

Анестетики

Антиаритмические препараты

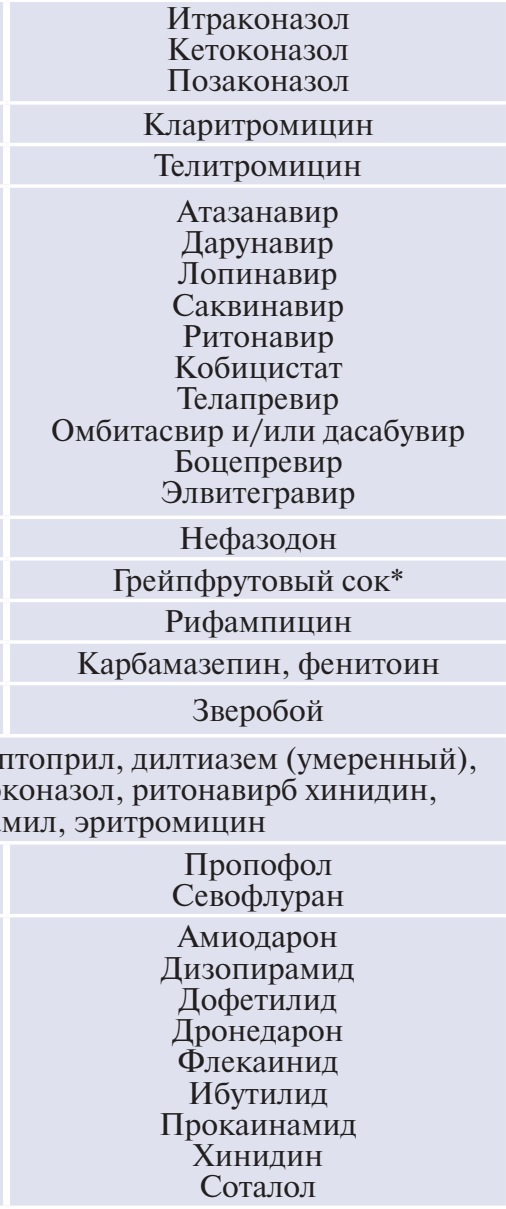


Окончание табл. 4

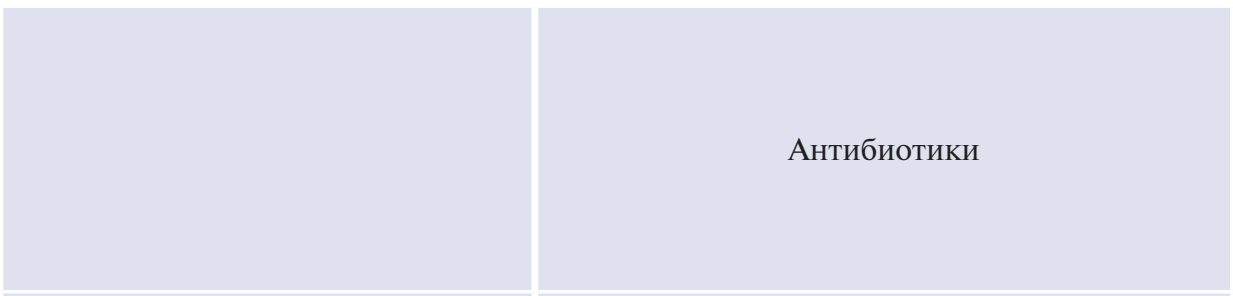

Противоопухолевые препараты

Антидепрессанты

Препараты, увеличивающие интервал QT

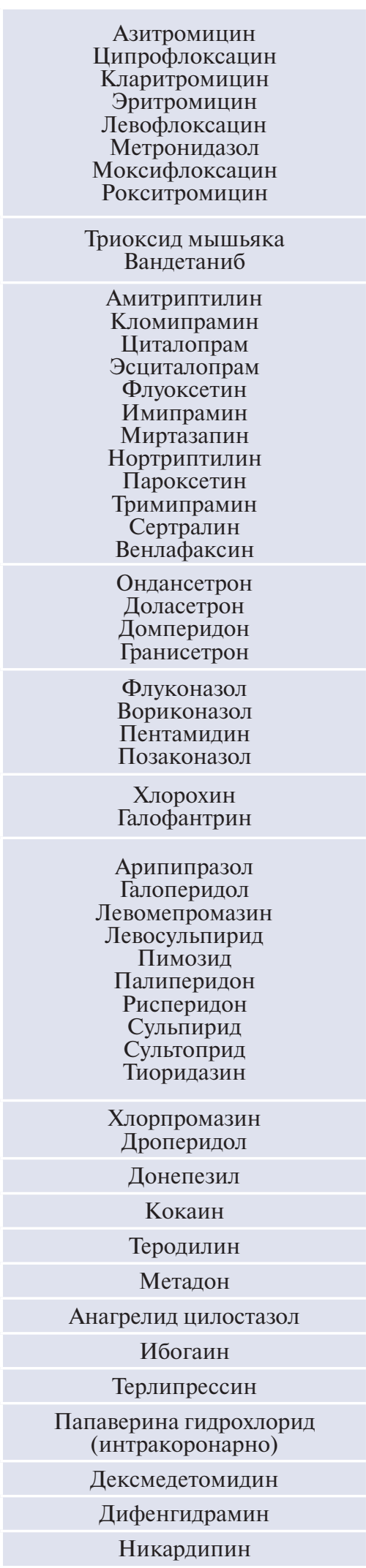

Противогрибковые препараты

Противомалярийные препараты

Антипсихотические препараты

\begin{tabular}{|c|}
\hline Противорвотные/ \\
\hline антипсихотические препараты \\
\hline Ингибитор холинэстеразы \\
\hline Местные анестетики \\
\hline Миорелаксанты \\
\hline Опиоидные антагонисты \\
\hline Ингибиторы фосфодиэстеразы 3 \\
\hline Психоделические препараты \\
\hline Сосудосуживающие препараты \\
\hline
\end{tabular}

Сосудорасширяющие, сердечные препараты

Другие седативные препараты

Антигистаминные препараты

Антагонисты кальция
Левофлоксацин

Метронидазол

оксифлоксацин

таниб

Циталопрам

италопрам

Имипрамин

Миртазапин

Венлафаксин

Ондансетрон

Доласетрон

Флуконазол

озаконазо.

Хлорохин

Арипипразол

Галоперидол

евомепромазин

Палиперидон

Рисперидон

Сультоприд

Дроперидол

Донепезил

Метадон

Ибогаин

ерлипрессин

верина гидрохло нтракоронарно)

Дексмедетомидин

Никардипин

* Можно считать сильным или умеренным ингибитором в зависимости от таких условий, как сила или концентрация. Примечание. ЛЕНЭВЕ - комбинация ленватиниб + эверолимус; $A U C$ - площадь под ROC-кривой. 
ленватиниба при совместном его применении с СҮРЗА, Р-гликопротеином (Р-gp) и индукторами СҮРЗА и Р-gp [28]. Более того, не обнаружено значительного влияния на фармакокинетику ленватиниба препаратов, способных повышать рН желудка, включая ингибиторы протонной помпы, блокаторы Н2-рецепторов и антацидные средства [30]. Для коррекции дозы эверолимуса нужно обратиться к инструкции по применению данного препарата. Необходимость использования препаратов, влияющих на интервал QT, также следует оценивать до и во время приема комбинации ЛЕНЭВЕ из-за возможного аддитивного эффекта.

\subsubsection{3. Легочная и сердечная функции}

Пациенты, у которых в анамнезе имеются заболевания легких, ассоциированные с ограничением их функциональности, должны пройти детальное обследование перед принятием решения о назначении комбинации ЛЕНЭВЕ. При наличии клинических признаков одышки нужно провести оценку функциональных возможностей легких. Также важно провести оценку сердечной деятельности (измерение фракции выброса левого желудочка и электрокардиография) до начала лечения у пациентов с риском развития сердечно-сосудистых заболеваний.

\subsubsection{4. Анализ крови}

Перед началом терапии следует провести полный анализ крови пациента, включающий определение уровней нейтрофилов, тромбоцитов, гемоглобина, печеночных ферментов, липидов и полный профиль гормонов щитовидной железы. Знание исходных значений поможет справится с цитопенией, токсическими реакциями со стороны печени [39] и гипотиреозом, которые могут быть вызваны приемом ленватиниба, а также с гиперметаболическим синдромом, связанным с приемом эверолимуса.

\subsection{2. Обучение пациента (и опекуна)}

Врач должен предоставить информацию о возможных побочных эффектах пациентам и лицам, осуществляющим уход за ними. Это может помочь снизить беспокойство пациента и повысить его уверенность в лечении и лечащем враче. Перед началом приема комбинации ЛЕНЭВЕ пациентам следует предоставить краткую, но исчерпывающую информацию с простыми инструкциями по профилактике или лечению побочных эффектов.

Обучение пациентов должно быть сосредоточено на информации о частоте и тяжести НЯ, способах их профилактики, которые помогут предотвратить их появление и снизить тяжесть частых НЯ, а также на советах относительно того, как активно контролировать возникающие токсические реакции с конкретными рекомендациями, когда следует обратиться за более ранней консультацией к лечащему врачу, а когда нужно срочно обратиться в отделение неотложной помощи.
На рис. 2 представлены краткие и простые инструкции, сформулированные на основе информации из инструкции по применению препаратов, и которые могут быть использованы в качестве учебного материала для пациентов в повседневной практике до начала лечения комбинацией ЛЕНЭВЕ. Кроме этого, важно давать рекомендации относительно образа жизни во время лечения, уделяя особое внимание пищевым привычкам, предпочтительным продуктам, частоте приема пищи, а также физическим упражнениям, если это возможно, чтобы избежать или снизить тяжесть некоторых токсических явлений на фоне приема ЛЕНЭВЕ (диарея, астения, усталость).

Наконец, для достижения максимальной эффективности терапии пациентов следует особенно поощрять за их приверженность к лечению и своевременный прием препаратов.

\section{2. Начальная фаза лечения (до стабилизации} дозы): раннее выявление нежелательных явлений, профилактические мероприятия и коррекщия дозы

Первый месяц лечения является ключевым для выбора подходящей для каждого больного дозы, а также для формирования уверенности в терапии у пациента и врача. В первый месяц пациенту желательно посещать врача (или связываться с ним по телефону) каждые 2 нед. Мониторинг возможной артериальной гипертензии наиболее важен на данном этапе. Следует учитывать комплаентность, добавление новых препаратов, НЯ и качество жизни пациента. На этом этапе также важно проводить обучение пациентов, мотивировать больного и его опекуна продолжать профилактический контроль НЯ. Раннее начало лечения новых НЯ поможет предотвратить их прогрессирование.

\section{3. Длительное лечение: периодический контроль и оценка ответа на терапию}

После первого месяца лечения и если доза была стабилизирована, пациенту рекомендовано посещать врача 1 раз в месяц, хотя данные временные рамки могут варьировать в зависимости от особенностей больного. Помимо пациентов с хорошей переносимостью терапии, будут и такие, которым может потребоваться более тщательное наблюдение из-за сопутствующих заболеваний или трудностей в коррекции НЯ. Грамотное ведение пациента требует индивидуального подхода с учетом особенностей больного. В случае подозрения на сердечную недостаточность каждые 3 мес необходимо выполнять электрокардиографию, каждые 6 мес - эхокардиографию. Также нужно выполнять регулярный (каждые 2 мес) контроль уровня гормонов щитовидной железы, если симптомы не проявляются раньше. Ответ на терапию следует мониторировать в соответствии с критериями RECIST с помощью компьютерной томографии органов грудной клетки и брюшной полости каждые 8-12 нед. 


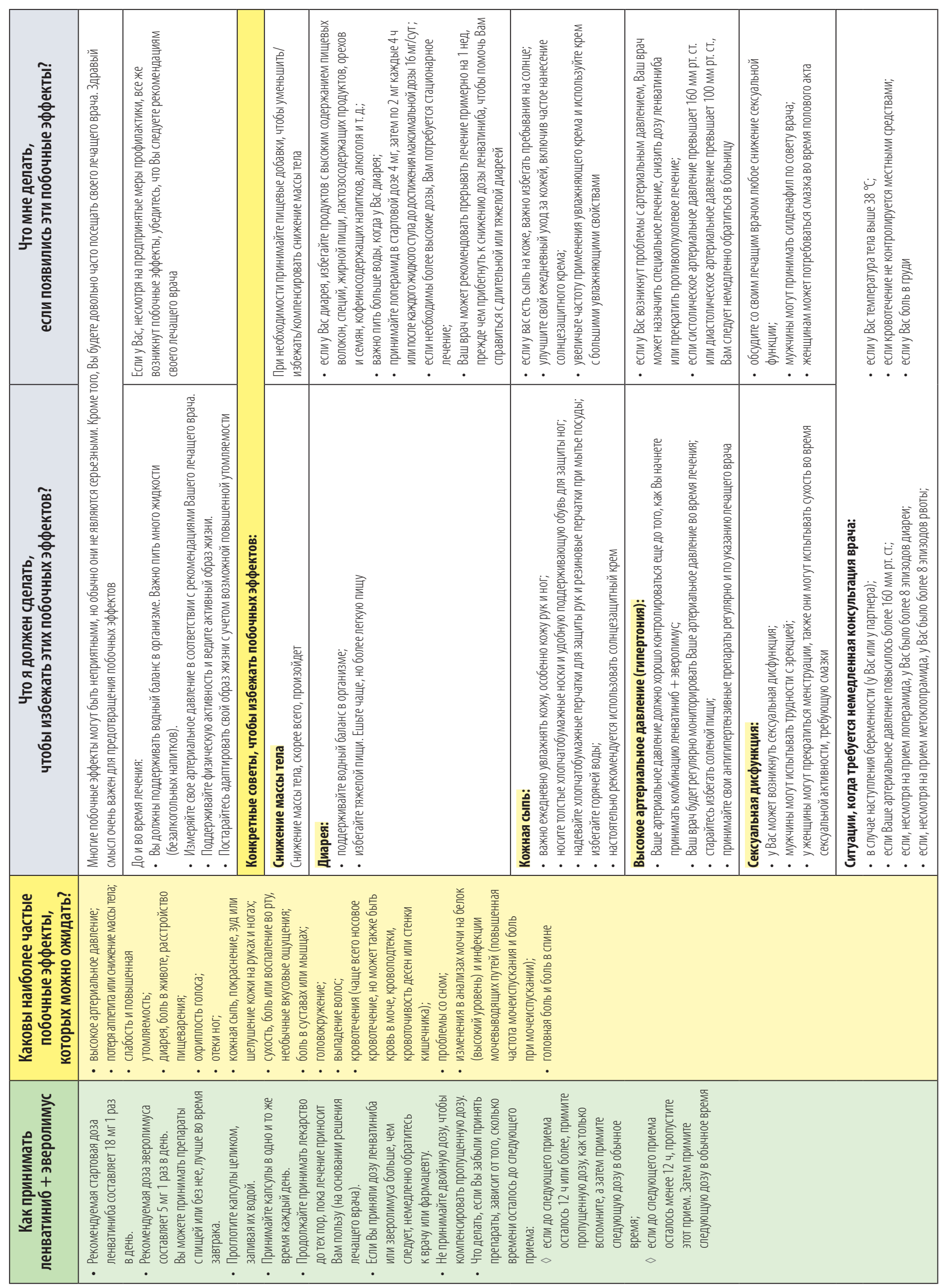




\section{4. Режим дозирования препарата: практические правила и рекомендации}

Рекомендуемая суточная доза ЛЕНЭВЕ составляет 18 мг ленватиниба (1 капсула по 10 мг и 2 капсулы по 4мг) 1 раз в день в сочетании с 5 мг эверолимуса 1 раз в день; оба препарата принимают внутрь независимо от приема пищи, запивая водой. В случае развития токсических реакций, дозы могут быть снижены для адаптации пациента и формирования у него толерантности (табл. 5). Важно понять, является ли причиной токсических реакций отдельный препарат или комбинация ЛЕНЭВЕ, а затем в соответствиИ с этим проводить коррекцию дозы.

В исследовании НОРЕ-205 у 36 (71 \%) пациентов, получавших комбинацию ЛЕНЭВЕ, потребовалось снизить дозу ленватиниба, что было проведено в течение первых 3 циклов лечения у 25 пациентов [10]. Медиана времени до первого снижения дозы составила 1,7 мес (интерквартильный диапазон 1,0-3,6 мес) [31]. Доза снижалась однократно у $29 \%$ пациентов, двукратно - у 23,5 \%, трехкратно - у 15,7 \%, 4 раза и более - у 2 \% [31]. Одному пациенту группы ЛЕНЭВЕ потребовалось снижение дозы эверолимуса [10]. Медиана суточной дозы составила 13,5 мг для ленватиниба (75,0 \% от изначально запланированной дозы 18 мг) и 4,7 мг для эверолимуса (93,6 \% от изначально запланированной дозы 5 мг) [26]. Финальные дозы ленватиниба распределились следующим образом: 18 мг у $29 \%, 14$ мг у $31 \%, 10$ мг у $23 \%, 8$ мг у $16 \%$ и 4 мг у $2 \%$ пациентов [26].

Дозы препаратов и режимы их введения должны подбираться в индивидуальном порядке вследствие высокой гетерогенности метаболизма лекарственных средств. Кроме этого, чтобы максимально повысить контроль над терапией, допускается временная отмена препаратов до тех пор, пока степень тяжести НЯ не снизится до I или менее. Может быть рассмотрено прерывание терапии на 1 или 2 нед, особенно в случае развития не тяжелых, но значительно влияющих на качество жизни НЯ. Сюда относятся мукозит, ладонно-подошвенная эритродизестезия, повышенная утомляемость, диарея II степени тяжести, т.е. те НЯ, которые могут быть купированы активным лечением. Рекомендации по дозам после возобновления лечения приведены ниже.

Кроме этого, в исследовании НОРЕ-205 активность ленватиниба в качестве монотерапии была весьма значительной. Так, по данным независимых экспертов, частота общего ответа в группе пациентов, принимавших только ленватиниб, составила $39 \%$ (по критериям RECIST), медиана выживаемости без прогрессирования - 9,0 мес (95 \% ДИ 5,6-10,2 мес), медиана ОВ - 18,4 мес (13,3 мес-не достигнута) [10, 11]. Следовательно, если во время лечения комбинацией ЛЕНЭВЕ у пациента развиваются ассоциированные с эверолимусом НЯ, следует рассмотреть возможность продолжения лечения только ленватинибом. Максимальная доза ленватиниба (как в комбинации ЛЕНЭВЕ, так и при монотерапии) должна поддерживаться как можно дольше, с учетом баланса между токсичностью и ожидаемым результатом.

\section{5. Когда следует прекратить лечение}

при отсутствии прогрессирования заболевания

Несмотря на отсутствие рентгенологических признаков прогрессирования заболевания, лечащий врач может решить, что ЛЕНЭВЕ больше не приносит пользы пациенту, и рекомендовать его отмену. Подобная рекомендация может быть дана в случае тяжелых и неконтролируемых токсических реакций, не поддающихся лечению, явного прогрессирования симптомов, ухудшения статуса пациента по шкале ECOG, сомнения в комплаентности и отзыва согласия пациентом. Перед принятием решения об отмене ЛЕНЭВЕ необходимо обязательно рассмотреть доступные опции последующей терапии и их ожидаемую переносимость. Если лечение комбинацией ЛЕНЭВЕ было прервано из-за токсических реакций, но нет никаких признаков прогрессирования заболевания, имеет смысл возобновить лечение ЛЕНЭВЕ, как только степень тяжести НЯ достигнет 0, I или приемлемой II, прежде чем начинать последующее лечение.

\section{7. Ленватиниб + эверолимус: практические рекомендации по лечению наиболее распространенных нежелательных явлений}

Токсические реакции I степени тяжести и хорошо переносимые реакции II степени тяжести не требуют модификации лечения, а лишь могут создать необходимость откладывания приема дозы или временного прерывания терапии в соответствии с клиническим заключением лечащего врача. Многие из часто встречающихся легких/умеренных токсических реакций можно контролировать с помощью сопутствующего лечения без необходимости приостанавливать прием ЛЕНЭВЕ, так как пациенту важно получить максимально возможную дозу. Например, возникновение артериальной гипертензии не требует прерывания приема ЛЕНЭВЕ, а скорее создает необходимость корректировки антигипертензивной терапии. Впервые зафиксированные токсические реакции II и III степени тяжести требуют прекращения приема как ленватиниба, так и эверолимуса до тех пор, пока степень тяжести НЯ не достигнет 0, I или приемлемой II. Если время, потребовавшееся для снижения степени тяжести НЯ до 0 или I, составляет менее 1 нед, рекомендуется продолжать прием в той же дозе при возобновлении лечения. Однако, если для устранения НЯ было необходимо прерывание лечения более чем на 1 нед, рекомендуется возобновить терапию с уменьшением 

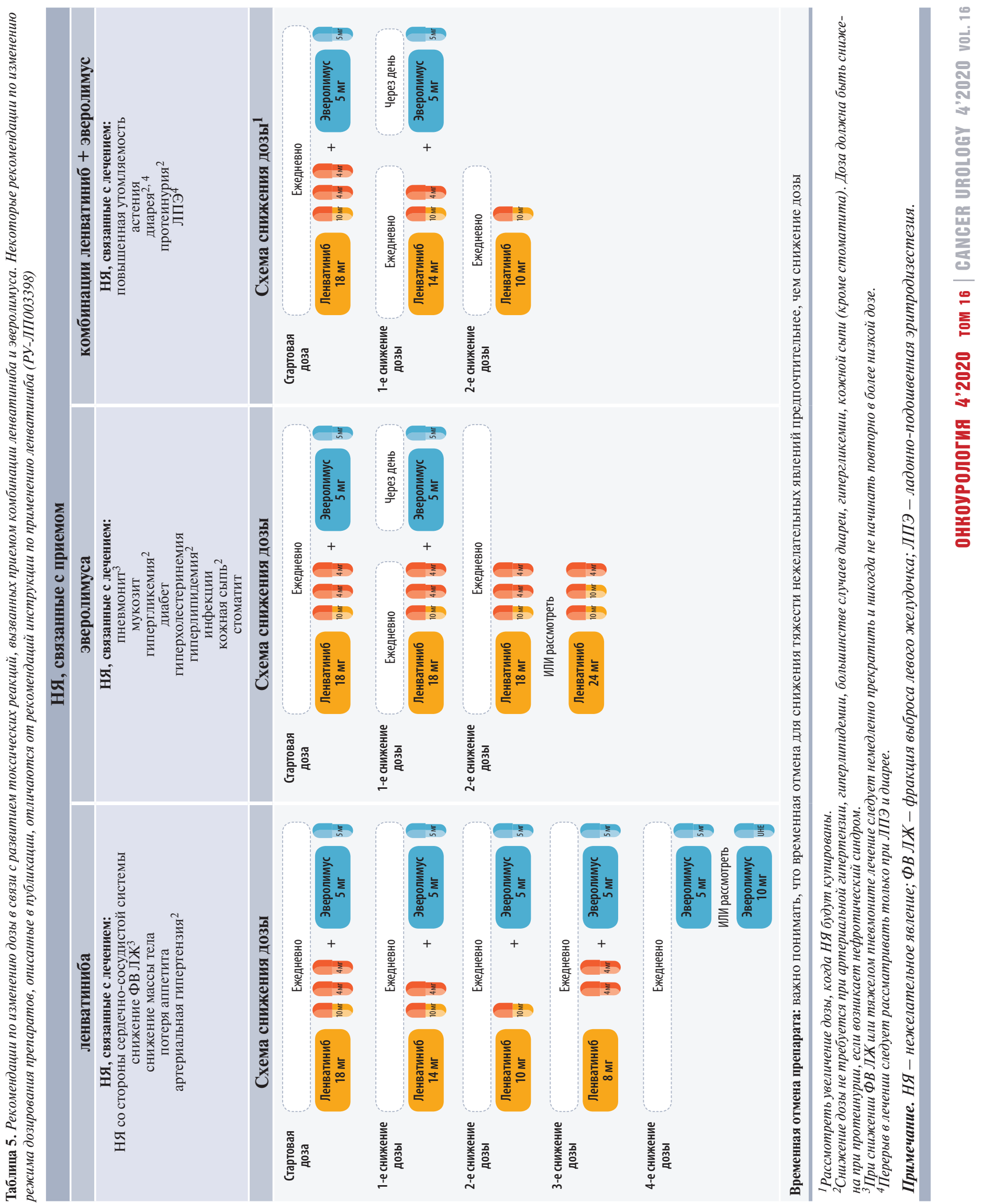
дозы на 1 уровень. В случае повторного возникновения НЯ также нужно прервать прием препарата до тех пор, пока степень тяжести не снизится до 0 , I или приемлемой II, но теперь снижение дозы будет обязательным при возобновлении лечения. Пациенты с токсическими реакциями IV степени тяжести должны немедленно прекратить лечение (табл. 6).

7.1. Сердечно-сосудистые нарушения (артериальная гипертензия, снижение фракции выброса левого желудочка, изменения на электрокардиограмме и др.) Нежелательные явления со стороны сердечно-сосудистой системы являются одними из наиболее распространенных токсических реакций, которые ожидаются при приеме комбинации ЛЕНЭВЕ. В исследовании HOPЕ-205 у 27 и $14 \%$ пациентов была зафиксирована артериальная гипертензия I-II и III степени тяжести соответственно $[10,11]$. Эти цифры подчеркивают важность ежедневного контроля артериального давления у пациентов, особенно в течение первого месяца лечения. При возникновении артериальной гипертензии следует в первую очередь скорректировать антигипертензивную терапию для решения проблемы; важно не прерывать лечение ЛЕНЭВЕ.

Костно-мышечная боль в грудной клетке наблюдалась у $16 \%$ пациентов, хотя у большинства она была легкой степени. Однако иногда такую боль в груди можно спутать с болями в сердце. Кроме того, у пациентов были случаи инфаркта миокарда. В отличие от других ИТК, ленватиниб, по-видимому, не вызывает удлинение интервала QTс с клинически значимой скоростью [40]. Пациентам с высоким риском развития синдрома удлиненного интервала QT, хронической сердечной недостаточности, брадиаритмии, а также пациентам, принимающим препараты, удлиняющие интервал QT (включая антиаритмики классов Іа и III), нужно регулярно выполнять электрокардиографию. Ленватиниб следует отменить в случае удлинения интервала QT >500 мс. Его прием можно возобновить в сниженной дозе, когда интервал QT достигнет значений $<480$ мс или исходного уровня.

\section{2. Общее состояние (астения, повышенная}

утомляемость, снижение аппетита, массы тела и др.)

Незначительная утомляемость или астения наблюдались у 45 \% пациентов, получавших комбинацию ЛЕНЭВЕ, причем еще $14 \%$ пациентов испытывали утомляемость III степени тяжести $[10,11]$. Утомляемость в данном случае связана с субъективным чувством эмоциональной, физической и/или когнитивной усталости, которая резко влияет на качество жизни пациентов, поэтому важны как ее профилактика, так и активное лечение. Для устранения связанной с приемом ЛЕНЭВЕ утомляемости следует в первую очередь контролировать причины усталости, такие как гипотиреоз, анемия, депрессия, нарушения сна или боль. Несмотря на то что специфического лечения усталости пока не разработано, есть данные, указывающие на потенциальную пользу от легких и умеренных физических упражнений, таких как ходьба, для повышения сопротивляемости, аппетита и улучшения сна. Двухнедельный перерыв в лечении может значительно улучшить состояние пациента, после чего прием ЛЕНЭВЕ может быть возобновлен в той же дозе. Такая стратегия лучше, чем попытки продолжать терапию в той же дозе без перерыва с усилением утомляемости, что в конечном итоге потребует снижения дозы. Другие подходы включают внимание к потреблению жидкости и адекватный режим питания. В редких случаях применяют системные препараты, в том числе стероиды, амфетамины, витаминные комплексы.

\section{3. Симптомы со стороны желудочно-кишечного} тракта (тошнота, рвота, диарея и др.)

Побочные явления, возникающие в результате изменений в желудочно-кишечном тракте, как правило, неприятны, но редко опасны для жизни. Адекватное медикаментозное лечение тошноты, рвоты и диареи должно быть начато до любого прерывания терапии или снижения дозы. НЯ со стороны желудочно-кишечного тракта обычно хорошо контролируются с помощью профилактических мероприятий, а раннее начало превентивного лечения может привести к разрешению таких симптомов. Наиболее частым НЯ у пациентов на фоне приема ЛЕНЭВЕ является диарея. В исследовании НОРЕ-205 до 85 \% пациентов, получавших ЛЕНЭВЕ, страдали от диареи, хотя у большинства больных (65 \%) степень тяжести не превышала I-II [10, 11]. В некоторых случаях диарея может контролироваться с помощью диеты, раннего назначения антидиарейных препаратов, соблюдения питьевого режима. Однако часто течение диареи может ухудшиться, несмотря на первоначальный ответ на профилактическое лечение лоперамидом и/или кодеином. Своевременный перерыв в лечении может полностью устранить НЯ со стороны желудочно-кишечного тракта и позволит возобновить прием препарата в той же дозе, что предпочтительнее, чем продолжение лечения с увеличением степени диареи и, в конечном счете, снижение дозы. Пациенты с персистирующей диареей, несмотря на эти меры, могут нуждаться в госпитализации для внутривенной регидратации. Кроме этого, тошнота и рвота тоже являются частыми НЯ при приеме ЛЕНЭВЕ: зарегистрированы у 41 и $45 \%$ пациентов соответственно.

\section{4. Нежелательные явления со стороны почек (протеинурия)}

Во время лечения ЛЕНЭВЕ следует регулярно проводить мониторинг протеинурии. В случае умеренной 


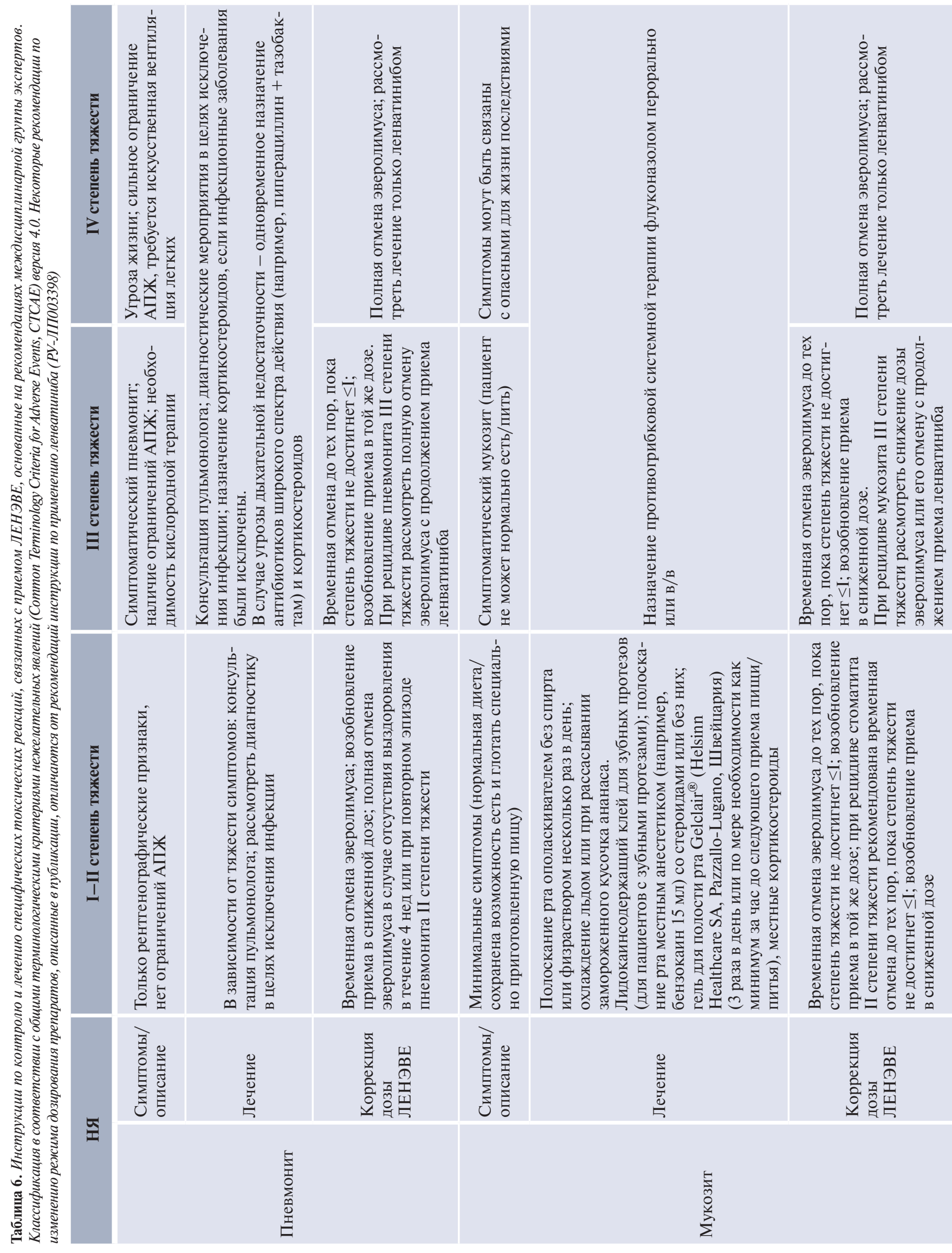



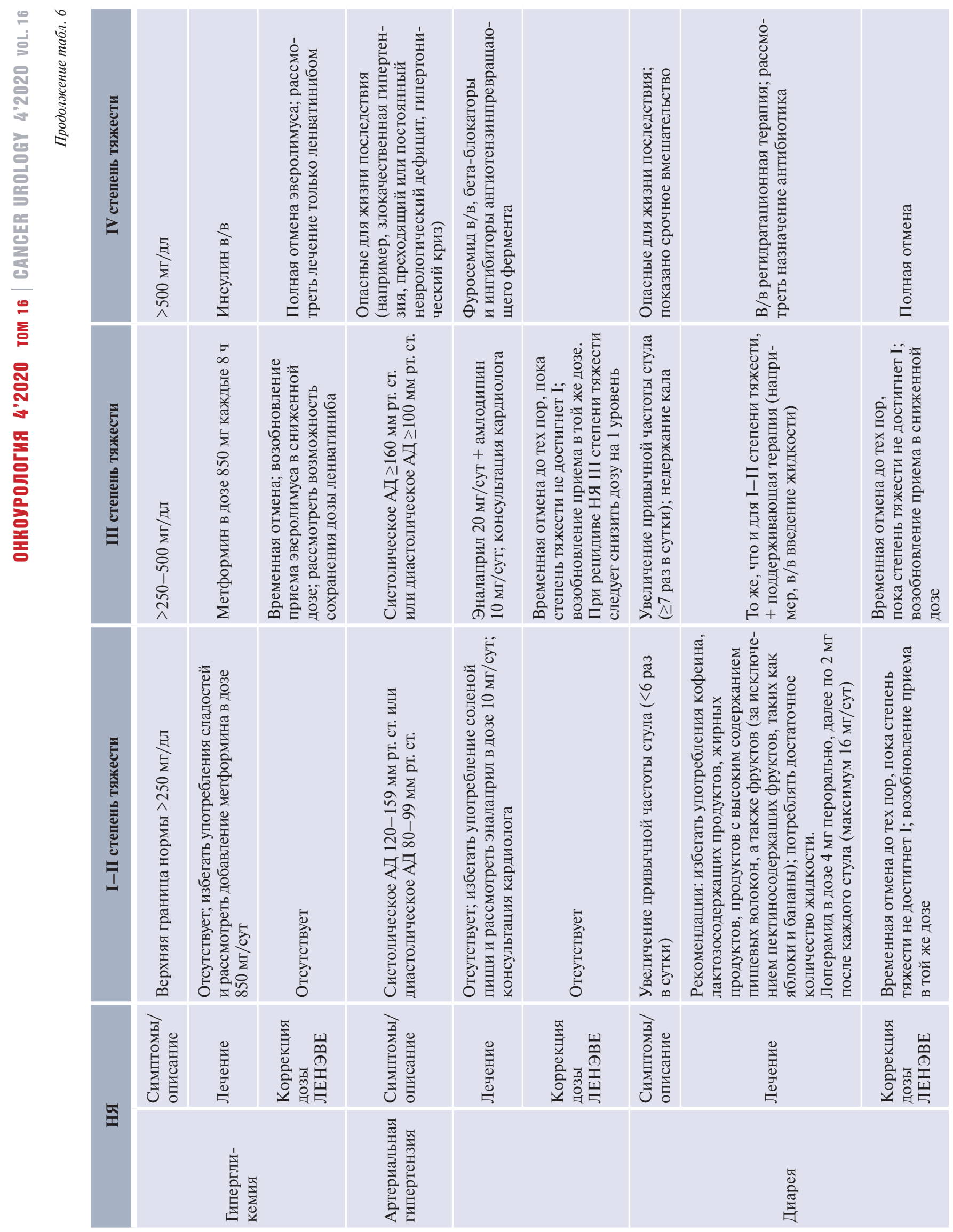


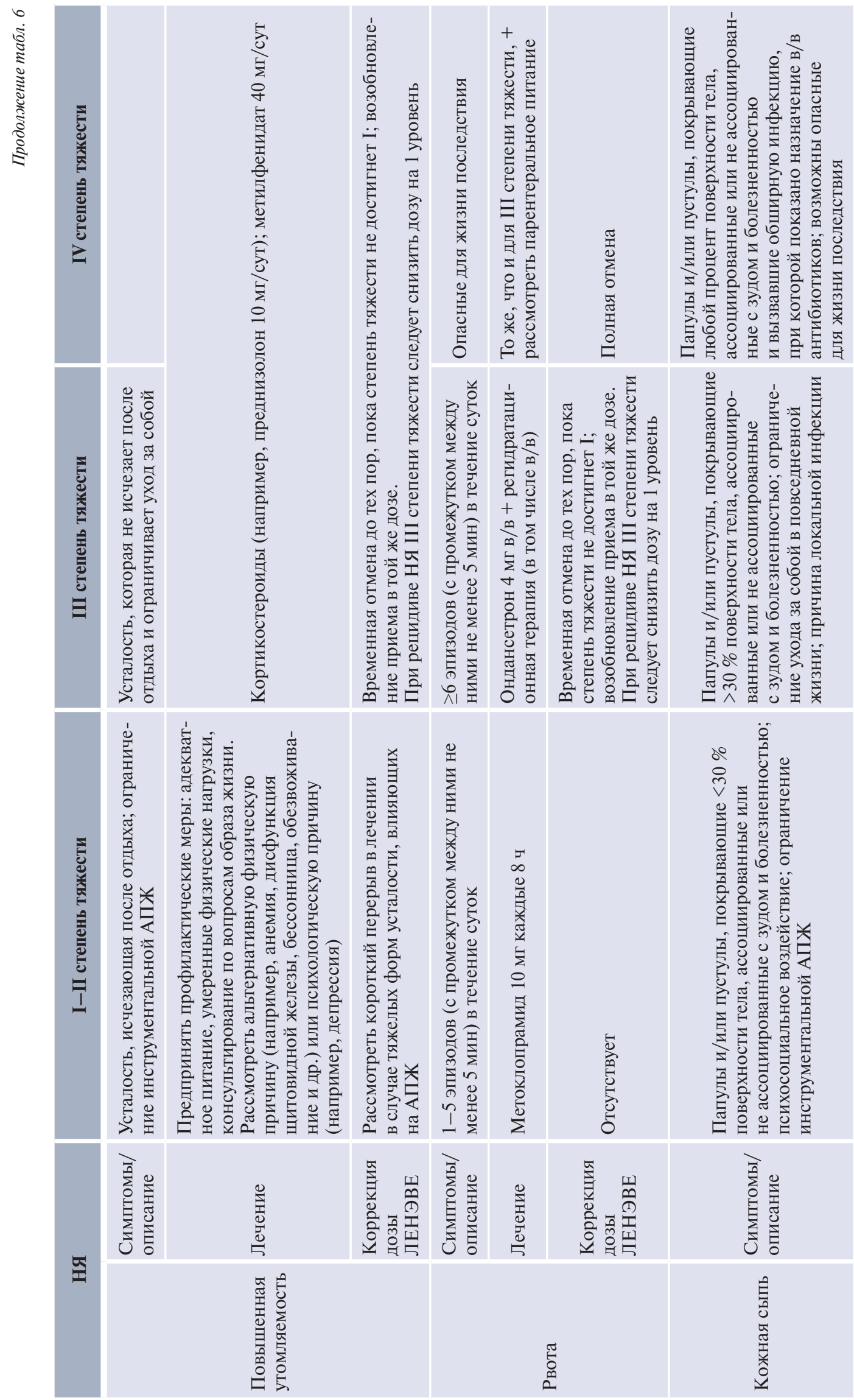




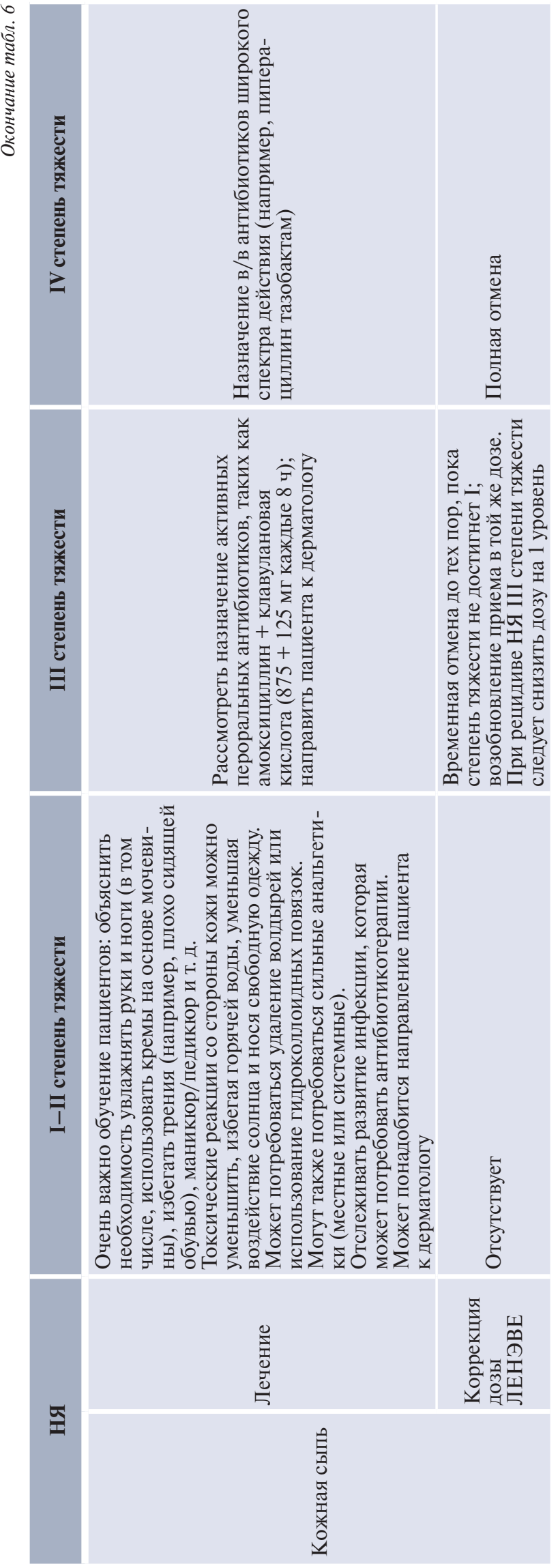

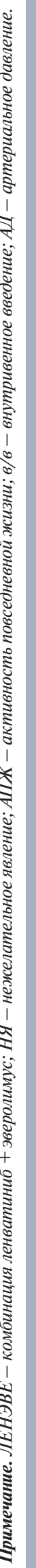

протеинурии, контроль может выполняться с помощью тест-полосок в клинике. Сбор суточной мочи в целях количественной оценки содержания белка необходим, если наблюдается $\geq$ II степень тяжести или протеинурия все еще возникает после снижения дозы. До 4 \% пациентов, получающих ЛЕНЭВЕ, страдают от протеинурии III или IV степени тяжести с последующим риском развития нефротического синдрома. У пациентов с легкой или умеренной почечной недостаточностью коррекции начальной дозы ЛЕНЭВЕ не требуется. Однако обострение скрытой почечной недостаточности является основным фактором риска развития диареи, поэтому крайне важно быстро и эффективно контролировать данное нарушение.

\section{5. Дерматологические реакции (ладонно- подошвенная эритродизестезия, сыпь, алопеция и др.)}

Несколько кожных реакций были в числе наиболее распространенных НЯ в исследовании HOPE-205. Кожная сыпь и ладонно-подошвенная эритродизестезия наблюдались у 18 и 8 \% пациентов соответственно $[10,11]$. Кроме этого, мукозит, вызванный главным образом эверолимусом, обнаруживался у 29 \% пациентов, получавших ЛЕНЭВЕ. Кожные высыпания редко требуют снижения дозы, а симптомы, как правило, уменьшаются с течением времени. В идеале пациентам следует рекомендовать уход за руками и ногами с начала лечения с использованием нейтральных увлажняющих кремов [41].

\section{6. Метаболические нарушения (гипергликемия, метаболический синдром и др.)}

Гипергликемия, гиперлипидемия и гипертриглицеридемия являются хорошо известными НЯ на фоне приема эверолимуса. Уровни глюкозы и липидов должны контролироваться еще до начала лечения ЛЕНЭВЕ. Во время терапии важно продолжать мониторинг, проводя частый контроль уровня глюкозы в крови. Как только появляются сомнения в том, что для контроля уровня глюкозы достаточно диеты, необходимо сразу же назначить лечение гипогликемическими препаратами.

\section{7. Респираторные нежелательные явления}

Неинфекционный пневмонит был зафиксирован у $19 \%$ пациентов, принимавших эверолимус в качестве монотерапии $[5,6]$. Однако в исследовании НОРЕ-205 пневмонит был диагностирован только у 1 пациента группы ЛЕНЭВЕ [10, 11]. Пневмонит может быть тяжелой степени и в редких случаях приводить к летальному исходу. Поэтому врачам следует рассмотреть возможность постановки диагноза неинфекционного пневмонита у пациентов 
с неспецифическими респираторными признаками и симптомами после исключения инфекционных, опухолевых и других немедикаментозных причин. В случае угрожающих жизни симптомов может потребоваться отмена эверолимуса.

\section{8. Сексуальная активность и беременность}

Женщины детородного возраста должны использовать высокоэффективную контрацепцию во время приема ЛЕНЭВЕ и после прекращения лечения. Большинство пациентов, принимающих таргетную терапию VEGF, испытывают сексуальную дисфункцию из-за снижения плотности капилляров - это классовый эффект [42, 43]. В начале лечения пациенты должны быть проинформированы о возможности возникновения сексуальных проблем, таких как эректильная дисфункция, нарушения мужского либидо, сухость влагалища и вульвовагинит $[44,45]$. Желательно задавать вопросы пациентам, не вызвало ли лечение проблем в отношении их сексуальной активности [46-48]. Предпочтительнее проводить скрининг сексуальных расстройств путем анкетирования (с вопросами о либидо, необходимости лубрикантов, диспареунии, эректильной дисфункции). Лечение сексуальной дисфункции не требует прекращения или модификации терапии [44, 45]. Может быть полезна консультация онколога-психолога и/или сексопатолога [44, 45]. Мужчинам с эректильной дисфункцией могут быть предложены ингибиторы ФДЭ-5.

\section{9. Другие нежелательные явления}

При возникновении у пациента кровотечения, связанного с тромбоцитопенией, рекомендуется прервать лечение с дальнейшим его возобновлением по усмотрению врача.

Возраст не является основанием для коррекции первоначальной дозы, хотя на сегодняшний день имеются лишь ограниченные данные о применении препарата у пациентов в возрасте $\geq 75$ лет. Наличие легкой (класс А по Чайлд-Пью) или умеренной (класс В по Чайлд-Пью) печеночной недостаточности также не требует коррекции начальной дозы. У пациентов с тяжелой печеночной недостаточностью (класс С по Чайлд-Пью) рекомендуемая начальная доза должна быть ниже с последующей коррекцией в зависимости от переносимости.

\section{8. Заключение}

Ведение пациентов всегда является сложной задачей при использовании онкологических препаратов, особенно в случае комбинированной терапии. Несмотря на хорошую переносимость отдельных компонентов, у некоторых пациентов комбинация ЛЕНЭВЕ может вызывать серьезные НЯ. Имея опыт, врачи смогут максимально оптимизировать лечение. Кроме этого, ленватиниб также, по-видимому, активен, когда используется в качестве монотерапии. Поэтому при наличии тяжелых НЯ при применении комбинации ЛЕНЭВЕ следует рассмотреть возможность продолжения лечения только ленватинибом.

Группа экспертов различных специальностей, занимающихся лечением пациентов с прогрессирующими опухолями с помощью как ИТК, так и ингибиторов mTOR, разработала данные рекомендации с простыми для выполнения повседневными инструкциями для пациентов, лиц, осуществляющих уход за ними, и врачей, имеющих дело с комбинацией ЛЕНЭВЕ. Мультидисциплинарный подход является ключевым для ведения этих больных, а оптимизация дозирования имеет решающее значение для максимально благоприятного клинического исхода.

В заключении отметим, что использование комбинации ЛЕНЭВЕ - одна из наиболее эффективных схем терапии, продлевающих жизнь пациентов с метастатическим ПКР, при этом ее переносимость может быть улучшена с помощью рекомендаций для пациентов, лиц, ухаживающих за ними, и врачей. Существуют простые способы, помогающие достичь наилучшего режима дозирования для пациента и поддерживать график введения препарата, что явно обеспечивает лучший клинический исход.

\section{9. Экспертное мнение}

Комбинация ЛЕНЭВЕ обеспечивает высокую частоту ответа на терапию и более длительную выживаемость по сравнению с эверолимусом в качестве монотерапии, но ассоциирована с большей токсичностью. Анализ имеющихся данных о профиле безопасности комбинации ЛЕНЭВЕ, применяемой в качестве терапии 2-й линии при ПКР показал, что большинство пациентов испытывали НЯ III или IV степени тяжести, включая такие наиболее распространенные токсические реакции, как диарея, повышенная утомляемость, астения, рвота и артериальная гипертензия. В результате многим пациентам требовалась временная или полная отмена лечения [10]. Поддержание интенсивности дозы путем соблюдения графика приема и сохранения оптимальной дозы препаратов является ключом к достижению наилучших результатов лечения. Кроме этого, применение междисциплинарного подхода к эффективному контролю токсических реакций еще более улучшает клинические результаты. Стремясь предоставить врачам практические инструкции по обучению пациентов, мониторингу и ведению пациентов с ПКР, получающих комбинацию ЛЕНЭВЕ, мы разработали следующие междисциплинарные рекомендации для использования в повседневной практике.

Перед назначением ЛЕНЭВЕ врач должен провести физикальное обследование пациента и проверить 
результаты анализа крови. Присутствующие до лечения сопутствующие заболевания, такие как гипертония или сахарный диабет, должны хорошо контролироваться еще до начала терапии. Несмотря на то что потенциал клинически значимых лекарственных взаимодействий ленватиниба считается достаточно низким, он может оказаться важным для эверолимуса. Важно распознавать лекарственные взаимодействия с препаратами, наиболее часто используемыми онкологическими больными, такими как антигипертензивные средства, противодиарейные препараты (лоперамид), препараты для лечения заболеваний щитовидной железы, антидепрессанты, антикоагулянты (варфарин, кумарол), опиаты и омепразол. Для того чтобы снизить тревожность, повысить уверенность пациентов и поощрить соблюдение режима лечения, необходимо разъяснить пациентам и лицам, осуществляющим уход, информацию в отношении ожидаемого профиля побочных эффектов. Следует предоставить краткую, но исчерпывающую информацию о частоте и тяжести НЯ, мерах профилактики для предотвращения развития и прогрессирования НЯ, а также советы о том, как активно контролировать возникающие токсические реакции с конкретными указаниями на то, когда следует обратиться за более ранней консультацией к лечащему врачу, а когда нужно обратиться в отделение неотложной помощи.

На начальном этапе лечения ленватинибом в комбинации с эверолимусом чрезвычайно важно подобрать оптимальную дозу, а также наладить регулярное взаимодействие с пациентом (в ходе визитов или по телефону), желательно каждые 2 нед в течение первого месяца. Мониторинг артериальной гипертензии является наиболее важным на этом этапе. Кроме этого, раннее начало лечения новых НЯ поможет предотвратить их прогрессирование в дальнейшем.

В дальнейшем, как только удастся добиться стабилизации дозы, регулярность последующих визитов может быть изменена в соответствии с потребностями пациента, но эти визиты должны включать выполнение электрокардиографии каждые 3 мес и анализ полного профиля гормонов щитовидной железы каждые 2 мес.

Лечебные дозы и график приема должны подбираться индивидуально для каждого пациента. При рассмотрении вопроса о снижении дозы ЛЕНЭВЕ важно учитывать, является ли отдельный препарат или комбинация ЛЕНЭВЕ причиной токсических реакций, и в соответствии с этим принимать решение о снижении дозы препаратов. Токсические реакции I степени тяжести и хорошо переносимые реакции II степени тяжести не требуют модификации лечения, а могут создать необходимость откладывания приема дозы или временной отмены терапии. Многие из часто встречающихся легких/умеренных токсических реакций можно контролировать с помощью сопутствующего лечения без необходимости прерывать прием ЛЕНЭВЕ. Впервые зафиксированные токсические реакции II и III степени тяжести требуют прерывания приема как ленватиниба, так и эверолимуса до тех пор, пока степень тяжести НЯ не достигнет 0, I или приемлемой II, после чего лечение может быть возобновлено в той же дозе, если перерыв не превысил 1 нед. Однако для пациентов, которым потребовалась более длительная отмена для восстановления, а также в случае повторного возникновения НЯ доза должна быть снижена на 1 уровень при возобновлении лечения. Пациенты с токсическими реакциями IV степени тяжести должны немедленно прекратить лечение.

Комбинация ЛЕНЭВЕ является эффективным режимом терапии, продлевающим жизнь пациентов с метастатическим ПКР. В настоящей статье мы приводим рекомендации по улучшению переносимости данной комбинации противоопухолевых препаратов, чтобы помочь пациентам достичь лучшего клинического исхода.

\section{Л И TEPAT У PA I REFERENCES}

1. Tilki D., Nguyen H.G., Dall'Era M.A. et al Impact of histologic subtype on cancerspecific survival in patients with renal cell carcinoma and tumor thrombus. Eur Urol 2014;66:577-83.

2. Hakimi A.A., Reznik E., Lee C.H. et al. An Integrated Metabolic Atlas of Clear Cell Renal Cell Carcinoma. Cancer Cell 2016;29:104-16.

3. Kim W.Y., Kaelin W.G. Role of $V H L$ gene mutation in human cancer. J Clin Oncol 2004;22:4991-5004.

4. Cancer Genome Atlas Research N. Comprehensive molecular characterization of clear cell renal cell carcinoma. Nature 2013;499:43-9.

5. Motzer R.J., Escudier B., Oudard S. et al. Phase 3 trial of everolimus for metastatic renal cell carcinoma: final results and analysis of prognostic factors. Cancer 2010;116:4256-65.

6. Motzer R.J., Escudier B., Oudard S. et al. Efficacy of everolimus in advanced renal cell carcinoma: a double-blind, randomised, placebo-controlled phase III trial. Lancet 2008;372:449-56.

7. Rini B.I., Escudier B., Tomczak P. et al. Comparative effectiveness of axitinib versus sorafenib in advanced renal cell carcinoma (AXIS): a randomised phase 3 trial. Lancet 2011;378:1931-9.

8. Calvo E., Schmidinger M., Heng D.Y. et al. Improvement in survival end points of patients with metastatic renal cell carcinoma through sequential targeted therapy. Cancer Treat Rev 2016;50:109-17.

9. Iacovelli R., Carteni G., Sternberg C.N. et al. Clinical outcomes in patients receiving three lines of targeted therapy for metastatic renal cell carcinoma: results from a large patient cohort. Eur J Cancer 2013;49:2134-42. 
10. Motzer R.J., Hutson T.E., Glen H. et al. Lenvatinib, everolimus, and the combination in patients with metastatic renal cell carcinoma: a randomised, phase 2 , open-label, multicentre trial. Lancet Oncol 2015;16:1473-82.

11. Motzer R.J., Hutson T.E., Ren M. et al. Independent assessment of lenvatinib plus everolimus in patients with metastatic renal cell carcinoma. Lancet Oncol 2016;17:e4-5.

12. Motzer R.J., Escudier B., McDermott D.F. et al. Nivolumab versus everolimus in advanced renal-cell carcinoma. N Engl J Med 2015;373:1803-13.

13. Choueiri T.K., Escudier B., Powles T. et al. Cabozantinib versus everolimus in advanced renal-cell carcinoma. N Engl J Med 2015;373:1814-23.

14. Choueiri T.K., Escudier B., Powles T. et al. Cabozantinib versus everolimus in advanced renal cell carcinoma (METEOR): final results from a randomised, open-label, phase 3 trial. Lancet Oncol 2016;17:917-27.

15. Cella D., Grunwald V., Nathan P. et al. Quality of life in patients with advanced renal cell carcinoma given nivolumab versus everolimus in CheckMate 025 : a randomised, open-label, phase 3 trial. Lancet Oncol 2016;17:994-1003.

16. Houk B.E., Bello C.L., Poland B. et al. Relationship between exposure to sunitinib and efficacy and tolerability endpoints in patients with cancer: results of a pharmacokinetic/pharmacodynamic meta-analysis. Cancer Chemother Pharmacol 2010;66:357-71

17. Kumar R., Knick V.B., Rudolph S.K. et al. Pharmacokinetic-pharmacodynamic correlation from mouse to human with pazopanib, a multikinase angiogenesis inhibitor with potent antitumor and antiangiogenic activity. Mol Cancer Ther 2007;6:2012-21.

18. Ornstein M.C., Wood L., Elson P. et al. Clinical effect of dose escalation after disease progression in patients with metastatic renal cell carcinoma. Clin Genitourin Cancer 2017; 15:e275-e80.

19. Rini B.I., Tomita Y., Melichar B. et al. Overall survival analysis from a randomized phase II study of axitinib with or without dose titration in first-line metastatic renal cell carcinoma. Clin Genitourin Cancer 2016;14:499-503.

20. Rugo H.S., Hortobagyi G.N., Yao J. et al. Meta-analysis of stomatitis in clinical studies of everolimus: incidence and relationship with efficacy. Ann Oncol 2016;27:519-25.

21. Boss D.S., Glen H., Beijnen J.H. et al. A phase I study of E7080, a multitargeted tyrosine kinase inhibitor, in patients with advanced solid tumours. Br J Cancer 2012;106:1598-604.
22. Yamada K., Yamamoto N., Yamada Y. et al. Phase I dose-escalation study and biomarker analysis of E7080 in patients with advanced solid tumors. Clin Cancer Res 2011;17:2528-37.

23. FDA Approves Drug Combo for Kidney Cancer. Cancer Discov 2016;6:687-8.

24. Nair A., Lemery S.J., Yang J. et al. FDA approval summary: lenvatinib for progressive, radio-iodine-refractory differentiated thyroid cancer. Clin Cancer Res 2015;21:5205-8.

25. Scott L.J. Lenvatinib: first global approval. Drugs 2015;75:553-60.

26. Kisplyx ${ }^{\circledR}$ (lenvatinib) [EPAR Product Information. Summary of Product Characteristics, EMEA/H/C/004224 -II/0001]. Eisai Europe Ltd.; 03/03/2017 [25/03/2017]. Available at: http://www.ema.europa.eu/docs/en_GB/ document_library/EPAR___Product_ Information/human/004224/ WC500216237.pdf.

27. StatBite: FDA oncology drug product approvals in 2009. J Natl Cancer Inst 2010;102:219.

28. Lenvima ${ }^{\circledR}$ (lenvatinib) [FDA prescribing information]. Eisai Inc; May 2016 [25/03/2017]. Available at: https://www.accessdata.fda.gov/ drugsatfda docs/label/2016/ 206947s0031bl.pdf.

29. Dubbelman A.C., Rosing H., Nijenhuis C. et al. Pharmacokinetics and excretion of (14)C-lenvatinib in patients with advanced solid tumors or lymphomas. Invest New Drugs 2015;33:233-40.

30. Gupta A., Jarzab B., Capdevila J. et al. Population pharmacokinetic analysis of lenvatinib in healthy subjects and patients with cancer. Br J Clin Pharmacol 2016;81:1124-33.

31. Kisplyx ${ }^{\circledR}$ (lenvatinib) [EPAR Procedural steps taken and scientific information after authorisation, EMA/578759/2016]. Eisai Europe Ltd.; 16/11/2016 [25/03/2017]. Available at: http://www.ema.europa.eu/docs/en_GB/ document_library/EPAR_-_Public_ assessment_report/human/004224/ WC500216286.pdf.

32. Al-Marrawi M.Y., Rini B.I., Harshman L.C. et al. International $\mathrm{m}$ RCCDC. The association of clinical outcome to first-line VEGF-targeted therapy with clinical outcome to secondline VEGF-targeted therapy in metastatic renal cell carcinoma patients. Target Oncol 2013;8:203-9.

33. Bracarda S., Sisani M., Marrocolo F. et al. GOAL: an inverse toxicity-related algorithm for daily clinical practice decision making in advanced kidney cancer. Crit Rev Oncol Hematol 2014;89:386-93.
34. Escudier B., Michaelson M.D., Motzer R.J. et al. Axitinib versus sorafenib in advanced renal cell carcinoma: subanalyses by prior therapy from a randomised phase III trial. Br J Cancer 2014; 110:2821-8.

35. Porta C., Tortora G., Linassier C. et al. Maximising the duration of disease control in metastatic renal cell carcinoma with targeted agents: an expert agreement. Med Oncol 2012;29:1896-907.

36. Sonpavde G., Choueiri T.K., Escudier B. et al. Sequencing of agents for metastatic renal cell carcinoma: can we customize therapy? Eur Urol 2012;61:307-16.

37. Roden D.M. Drug-induced prolongation of the QT interval. N Engl J Med 2004;350:1013-22.

38. Keller K.L., Franquiz M.J., Duffy A.P., Trovato J.A. Drug-drug interactions in patients receiving tyrosine kinase inhibitors. J Oncol Pharm Pract 2016.

39. Shumaker R., Aluri J., Fan J. et al. Influence of hepatic impairment on lenvatinib pharmacokinetics following single-dose oral administration. J Clin Pharmacol 2015;55:317-27.

40. Shumaker R.C., Zhou M., Ren M. et al. Effect of lenvatinib (E7080) on the QTc interval: results from a thorough QT study in healthy volunteers. Cancer Chemother Pharmacol 2014;73:1109-17.

41. Valle J.W., Faivre S., Hubner R.A. et al. Practical management of sunitinib toxicities in the treatment of pancreatic neuroendocrine tumors. Cancer Treat Rev 2014;40:1230-8.

42. Lysiak J.J., Kavoussi P.K., Ellati R.T. et al. Angiogenesis therapy for the treatment of erectile dysfunction. J Sex Med. 2010;7:2554-63.

43. Villalba N., Kun A., Stankevicius E., Simonsen U. Role for tyrosine kinases in contraction of rat penile small arteries. J Sex Med. 2010;7:2086-95.

44. Bessede T., Massard C., Albouy B. et al. Sexual life of male patients with advanced renal cancer treated with angiogenesis inhibitors. Ann Oncol 2011;22:2320-4.

45. Bessede T., Joly F., Lebret T. Management of side effects of targeted therapies in renal cancer: sexual disorders. Bull Cancer 2011;98:S127-31.

46. Hautamäki-Lamminen K., Lipiäinen L., Beaver K. et al. Identifying cancer patients with greater need for information about sexual issues. Eur J Oncol Nurs 2013;17:9-15.

47. Coady D., Kennedy V. Sexual health in women affected by cancer: focus on sexual pain. Obstetric Gynecol 2016;128:775-91.

48. Gilbert E., Perz J., Ussher J.M. Talking about sex with health professionals: the experience of people with cancer and their partners. Eur J Cancer Care 2016;25:280-93. 